\title{
High temperature resistant properties of polyimide coated optical fibre
}

\author{
C DONGRE, G YADAV and G BUDHOLIA*+ \\ Macromolecular Research Centre, R. D. University, Jabalpur 482001, India \\ ${ }^{\dagger}$ Present Address: Department of PG Studies and Research in Chemistry, Rani Durgavati \\ Vishwavidyalaya, Jabalpur 482001, India \\ MS received 29 December 1994; revised 29 January 1996

\begin{abstract}
Optical fibres were coated with polypyromellitimide (PPM) using their precursor polyamic acid to study the application of optical fibres at elevated temperatures. Normally optical fibres can withstand temperatures in the range of $100-200^{\circ} \mathrm{C}$ but our studies have indicated that optical fibre coated with PPM can easily withstand temperatures up to $400^{\circ} \mathrm{C}$ without any loss. Interaction of silica with polyamic acid has been suggested with the formation of water and thus it is presumed that damaging hydrogen is not being formed. Characterization of the coated optical fibre has been done with the help of FT-IR and TG
\end{abstract} \\ analysis.
}

Keywords. Polypyromellitimide: optical fibre: polymeric coating: high temperature resistant.

\section{Introduction}

Optical fibre materials are extremely delicate due to poor mechanical properties and are also susceptible to physical damages and optical transmission losses. Therefore, the performance properties of optical fibres used in telecommunication applications are strongly influenced by the polymer coatings applied during fibre drawing. The primary function of the coating is to protect the glass fibre from external sources of abrasion and contamination and thus preserve its intrinsic strength. To meet the high temperature requirement in optical fibre telecommunication industry, the coatings comprising metal oxides, metals and high temperature resistant polymeric materials on optical fibre are currently growing in demand. The use of this type of coated fibre includes aircraft, automotive, medical and for other advance purposes. Dielectric metallic and polymeric materials are considered for high temperature coatings. In the case of dielectric coatings such as oxides, nitrides and carbides, the coating thickness is generally less than $1 \mu \mathrm{m}$. For long lengths dielectric coated fibres are further protected by an additional polymeric coating. Therefore, even though the dielectric coating can withstand fairly high temperatures, the application of dielectric/polymeric coated fibres will be limited to the temperature rating of polymer.

In the case of metallic coatings the coating thickness can be as high as $25-30 \mu \mathrm{m}$ and an additional polymeric coating is not required for handling purposes. Low temperature melting metals like indium, tin, aluminium (Dyott $e t$ al 1987) and high temperature melting metals like gold and copper are successfully used as coatings on optical fibres. Metal fibre coating has been successfully used to hermetically seal fibres (Pinnow et al 1979). Such fibres exhibit dramatically improved durability. However, hermetically sealed fibres that can survive the required proof test levels have low reproducibility. In the case of polymeric coatings which are commonly applied ultraviolet cured epoxy acrylate can withstand up to $100^{\circ} \mathrm{C}$ whereas silicone (Wada et al 1986) and ladder silioxane polymer (Araki et al 1988) can withstand nearly $200^{\circ} \mathrm{C}$. Biswas (1990) has 
shown that for temperatures greater than $200^{\circ} \mathrm{C}$ polyimide is becoming an attractive candidate, which is capable of withstanding $300^{\circ} \mathrm{C}$ to $400^{\circ} \mathrm{C}$ temperature. It has excellent thermal stability, chemical resistance and good dielectric properties. Biswas and Roland (1990) reported that polyimide coated fibres showed excellent optical and mechanical performance on exposure to air at $300^{\circ} \mathrm{C}$. In this communication we report the spectroscopic and thermal characterization aspects of polypyromellitimide, a high temperature resistant condensation polyimide coating used for optical fibres and also the structural changes in polyimide due to interaction with active surface of the optical fibres.

\section{Experimental}

A $10 \%$ solution of precursor polyamic acid of polypyromellitimide (PPM) has been made by stoichiometric ratio of pyromellitic dianhydride and diaminodiphenyl ether in DMAc (dimethylacetamide) solvent. The synthesis of polypyromellitimide (PPM) is as follows:

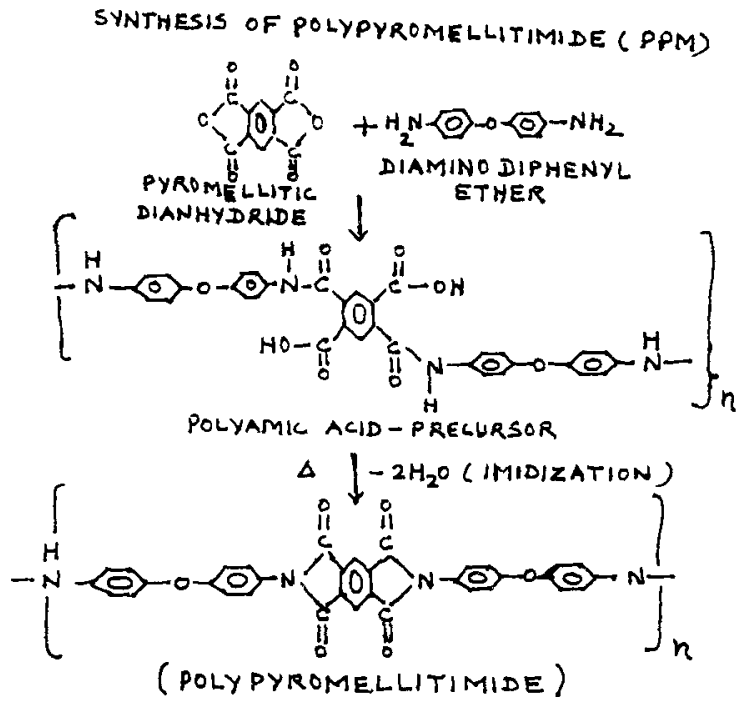

Precursor polyamic acid has been coated by solution casting technique over optical fibre filament of $125 \mu \mathrm{m}$ diameter (Doped silica core with nominal diameter of $10 \mu \mathrm{m}$ and silica cladding with nominal diameter of $125 \mu \mathrm{m}$ and a base optical fibre was supplied by $\mathrm{M} / \mathrm{s}$ Optel Telecommunications Ltd., Bhopal, M.P.) For this purpose inhouse developed coating equipment is applied as shown in figure 1. Polyamic acid has been used for coating the fibre in liquid phase by dipping method followed by hardening of the plastics. The dipping method is hard to form a concentric and uniform coating layer (Sakaguchi et al 1981). In the coating equipment we employed an automatic centring system in line with coating thickness measurement to maintain a good concentricity and a desired uniform thickness of coating. The typical thickness of the coating is $\sim 50 \mu \mathrm{m}$ (at a low coating speed $V=\sim 1 \mathrm{~m} / \mathrm{min}$ ) and the residence time of fibre in coating solution is $10 \mathrm{~min}$ (Paek and Schroeder 1985). 


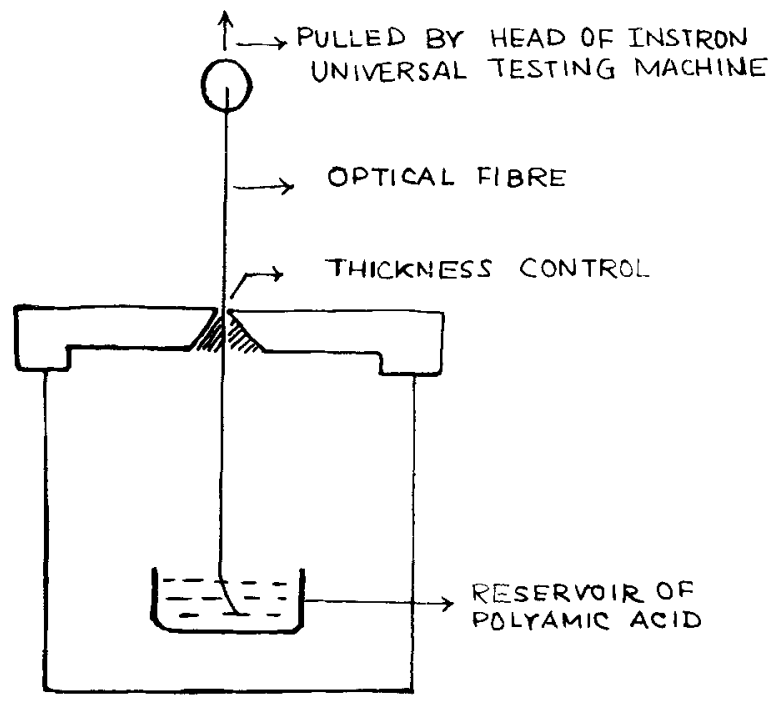

Figure 1. Coating equipment.

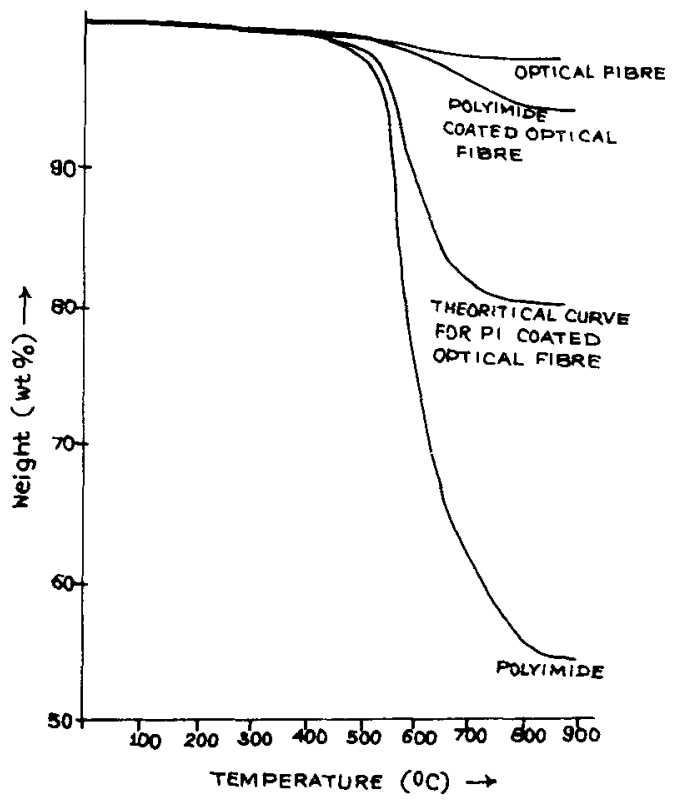

Figure 2. Thermogram of optical fibre, polyimide coated optical fibre, theoretical curve for PI coated optical fibre and polyimide.

The solvent evaporation and the imidization of the polyamic acid coating has been carried out by raising step by step the temperature up to $260^{\circ} \mathrm{C}$ and maintaining the temperature for $2 \mathrm{~h}$ in the oven. FT-IR spectrum using Perkin Elmer $1720 \times$ spectrometer of the polyimide coating was obtained by carefully scratching out the polymer from coated optical fibre and compared with the spectrum of the control sample prepared under identical conditions. PPM coated optical fibre has been subjected to thermogravimetric analysis by using Perkin Elmer-7 series thermo analyzer. 


\section{Results and discussion}

Based on the results of the thermal studies following inferences can be seen (figure 2).

(I) Bare optical fibre is thermally stable with only $2.5 \%$ loss of weight up to $900^{\circ} \mathrm{C}$ which is attributed to the loss of adsorbed water or elimination of water due to the reaction of silanol $(\mathrm{Si}-\mathrm{OH})$ functionality present in silica optical fibre. This presence of silanol group is indicated by FT-IR spectrum of optical fibre.

(II) As indicated by initial decomposition temperature in TGA curve, PPM coated optical fibre is as thermally stable as PPM itself. However, the rate of decomposition is slower in the case of coated fibre. This is attributed to amic acid reaction with silanol groups in silica material. It will be worthwhile to mention at this stage that the interaction of polyamic acid with silica generates water molecules and thus avoids the generation of hydrogen which is normally observed when optical fibres are being heated with different materials like silicone and acrylated resins (Noguchi et al 1984). Hydrogen thus generated is the main source of damaging the cables during their applications.

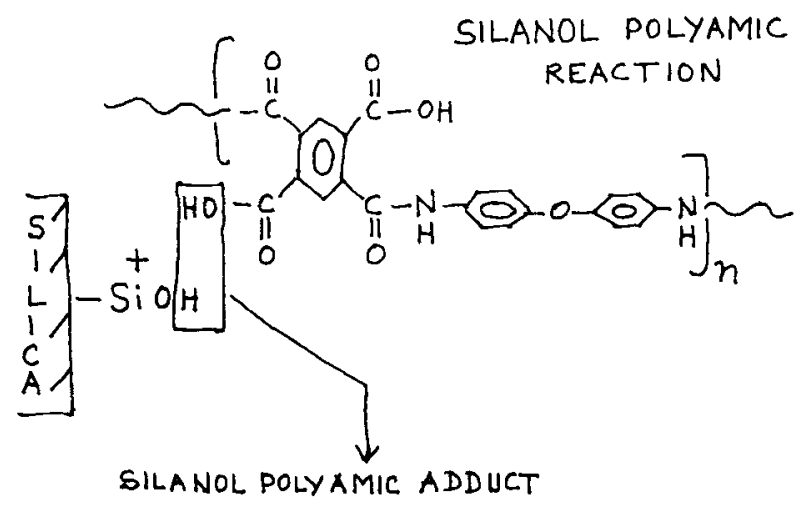

(III) Gupta et al (1991) suggested that the residue left at $900^{\circ} \mathrm{C}$ is higher in the case of coated fibre which is again attributed to cross-linking introduced due to silanol reaction with polyamic acid.

(IV) In the case of polyimide, it is clear from figure 2 that the thermal degradation of pure polyimide starts at $500^{\circ} \mathrm{C}$. Maximum weight loss of $45 \%$ is observed at $900^{\circ} \mathrm{C}$ with $55 \%$ of the residue left behind.

(V) As PI coated optical fibre degrades up to $6 \%$, therefore, for this a theoretical curve is calculated because the optical fibre and PI are in the ratio $60: 40$. If $40 \%$ is considered as 100 , then according to polyimide curve $45 \%$ of 40 will be $20 \%$ by wt. Hence, a thermal stability of PI coated optical fibre is increased.

The spectroscopic results (figures 3A, B) (Mauritz and Warren 1989) and figure 3C (Lee 1984) have revealed that the nature of the coating remains same with respect of imide content. The symmetric stretching vibration of the $\mathrm{Si}-\mathrm{O}-\mathrm{Si}$ group is present in the region $800 \mathrm{~cm}^{-1}$. This has also proved that there is no change in the optical fibre material (i.e. silica). 
Thermal testing was carried out on polyimide coated fibres by TGA and OIT (oxygen induction test) methods. The sample weight subjected to TGA was $3.156 \mathrm{mg}$ at $550^{\circ} \mathrm{C}$. The result at the above temperature showed $40 \%$ residue of the initial weight.

IR of powder of polyimide coated fibre showed imide peak in the region of $1776 \mathrm{~cm}^{-1}$ and $\mathrm{Si}-\mathrm{O}-\mathrm{Si}$ peak in $800 \mathrm{~cm}^{-1}$ region. This shows that the coating remains same in respect of imide content and no change occurs in the optical fibre material (i.e. silica).

\section{Conclusions}

The following major conclusions are drawn from the executed analysis:

(1) Ease and thickness of coating can be adjusted as desired.

(2) Thermal stability of PPM coated fibre is better than pure PPM.

(3) IR and TGA studies indicate the interaction of polyamic acid with silica glass which is a favourable phenomenon.

(4) Thickness of the coated layer of PPM over optical fibre cannot be calculated by only TGA studies, unlike epoxy acrylate.

(5) PPM coating can withstand temperatures nearly up to $400^{\circ} \mathrm{C}$ on optical fibres. This is the highest temperature resistant coating material known at present.

(6) If these polyimide coated fibres are further protected by high temperature cabling materials, they can be suitable for different high temperature applications for even longer periods of time.

(7) Since the interaction of silica with polyamic acid is through the generation of water molecules, it is presumed that no hydrogen is generated which usually imparts damaging effects to optical fibres.

(8) Polyimide is an excellent barrier for moisture.

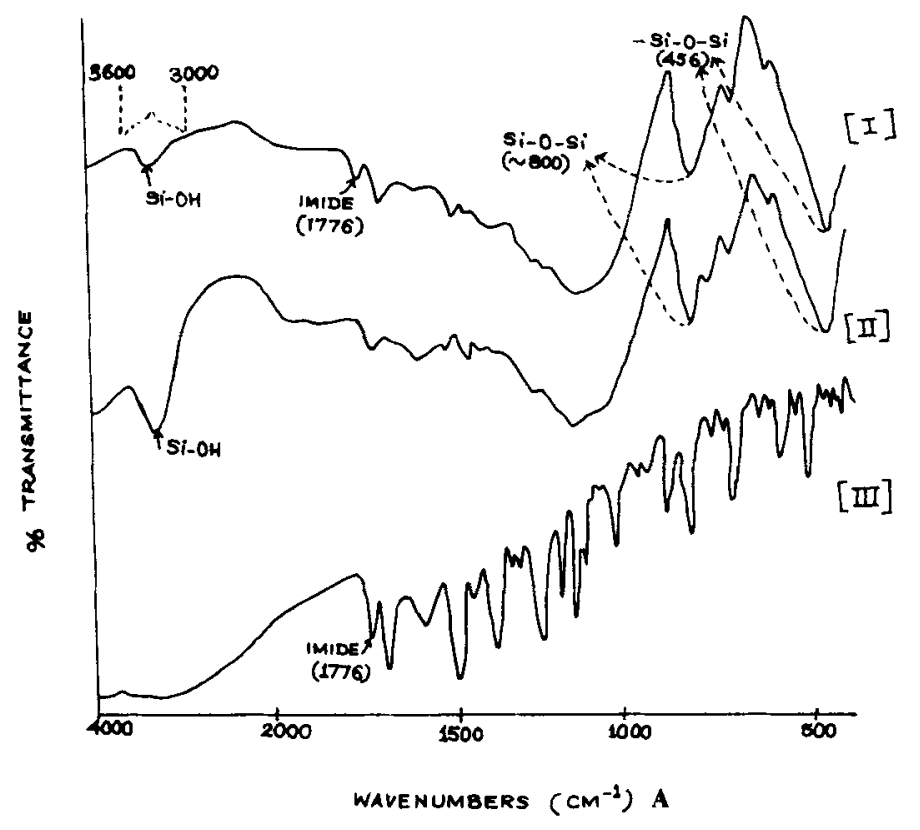

Figure 3. A. 

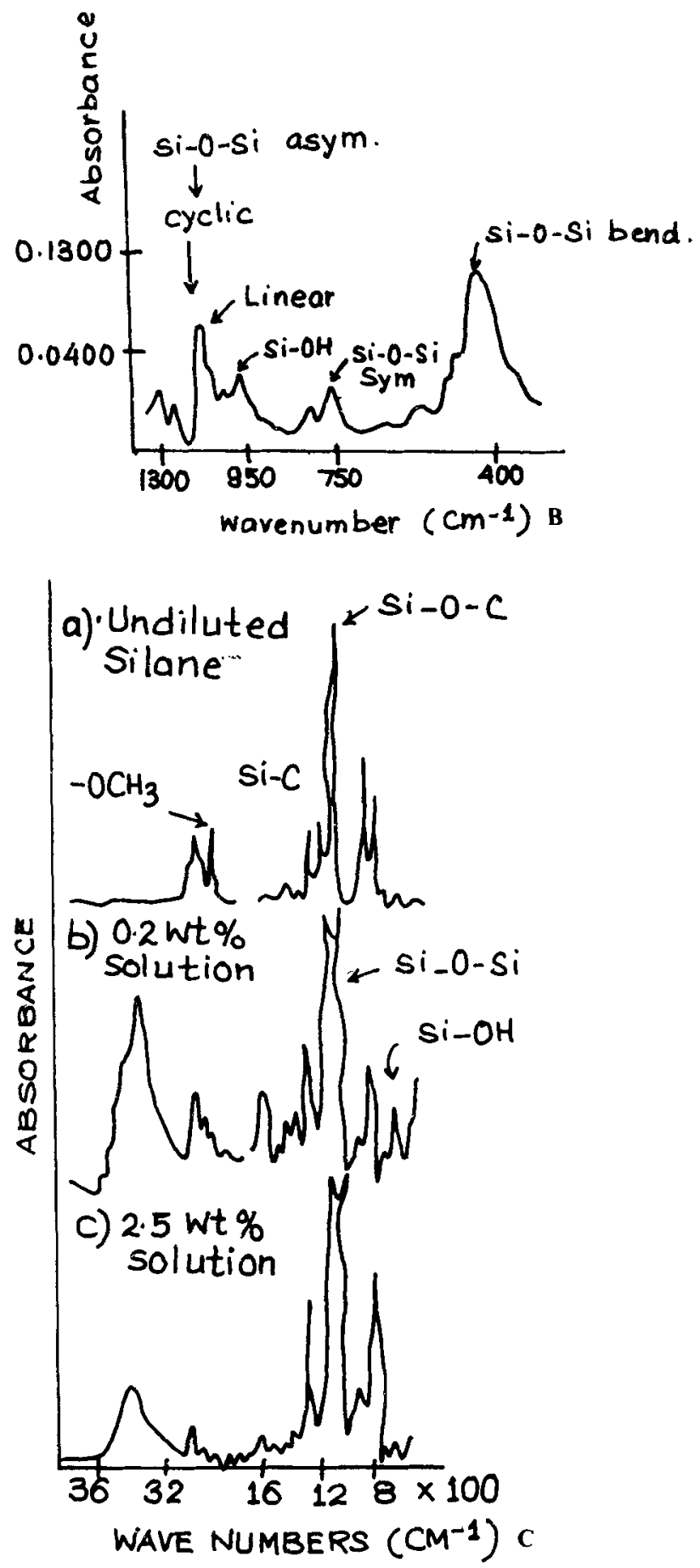

Figure 3. A. FT-IR spectra of (I) polyimide coated optical fibre, (II) bare optical fibre heated at $260^{\circ} \mathrm{C}$ and (III) polyimide, B. FT-IR (ATR) spectra with vibrational band assignments of Nafion-based micro-composites having indicated silicon oxide and $\mathbf{C}$. IR spectra of methyl (trimethoxy) silane: a. undiluted and deposited from aqueous solution, b. $0.2 \mathrm{wt} \%$ and $\mathbf{c}$. $2.5 w t \%$. 


\section{Acknowledgements}

The authors thank the Madhya Pradesh Council for Science and Technology, Bhopal and $\mathrm{M} / \mathrm{s}$ Optel Telecommunications Ltd., Bhopal for financial assistance. Authors also thank MRC colleagues for their help in thermal and FT-IR analysis and for their valuable cooperation throughout the work.

\section{References}

Araki Set al 1988 Proc. 37th IWCS p. 745

Biswas D 1990 OFC Tech. Digest THH3 173

Biswas D R and Roland D K 1990 Proc. 39 th IWCS p. 722

Dyott R B, Bello J and Handerek V A 1987 Opt. Lett. 12287

Gupta M. Tiwari S K, Bajpai U D N and Nema S K 1991 in Polymer science: Contemporary themes (ed.) S Sivaram (New Delhi: McGraw Hill) 1 p. 87

Lee L H (ed.) 1984 Effect of silane on giass/resin adhesion strength, in Adhesive chemistry: development and trends (Plenum Press) 29 p. 143

Mauritz K A and Warren R M 1989 Macromolecules 221730

Noguchi K, Uesugi N and Ishihara K 1984 Electronics Lett. 22897

Paek U C and Schroeder C M 1985 J. Lightwave Technol. LT3 1056

Pinnow D, Roberson G D, Blair G R and Wysocki J A 1979 Advances in high-strength metal-coated fibre optical waveguides, Optical fibre communications (Washington DC: Topical Meeting Digest) pp 28-30

Sakaguchi S, Kimura T and Nakahara M 1981 Electron. Lett. 1715

Wada A et al 1986 OFC Tech. Digest TUIS 42 